$04 ; 11$

\title{
Долговременная воспроизводимость эмиссионных характеристик алмазографитовых полевых источников электронов в нестационарных вакуумных условиях эксплуатации
}

\author{
(ㄱ Р.К. Яфраров ${ }^{1,2}$, А.В. Сторублев ${ }^{2,3}$ \\ ${ }^{1}$ Саратовский филиал Института радиотехники и электроники им. В.А. Котельникова РАН, Саратов, Россия \\ ${ }^{2}$ Саратовский национальный исследовательский государственный университет им. Н.Г. Чернышевского, Саратов, Россия \\ ${ }^{3} \mathrm{AO}$ „НПП “Алмаз“, Саратов, Россия \\ E-mail: pirpc@yandex.ru
}

Поступило в Редакцию 25 мая 2021 г.

В окончательной редакции 12 сентября 2021 r.

Принято к публикации 14 сентября 2021 г.

\begin{abstract}
Приведены результаты исследования долговременной воспроизводимости эмиссионных характеристик полевых источников электронов на основе композитных наноуглеродных пленочных покрытий с плотностью автоэмиссионного тока более $1000 \mathrm{~A} / \mathrm{cm}^{2}$. Установлено, что полевая эмиссия с высокой плотностью автоэмиссионного тока сопровождается распылением ионами остаточного газа атомов материала автокатода и его переосаждением на анод. Результаты могут быть использованы для прогнозирования срока службы алмазографитовых автокатодов при эксплуатации в нестационарных температурно-вакуумных условиях.
\end{abstract}

Ключевые слова: алмазографитовый нанокомпозит, сильноточная полевая эмиссия, воспроизводимость параметров вольт-амперных характеристик, срок службы.

DOI: 10.21883/PJTF.2021.24.51792.18883

Электровакуумные приборы СВЧ-, суб- и терагерцевого (THz) диапазонов имеют широкое применение как в наземных, так и в воздушно-космических радиотехнических устройствах. Наряду с повышением рабочей частоты, мощности и обеспечением мгновенного времени готовности систем навигации и космической связи ставятся задачи увеличения их надежности и срока службы в десятки и сотни тысяч часов [1]. Освоение THz-диапазона осуществляется с помощью приборов твердотельной либо вакуумной эмиссионной электроники. Однако ограничения на реализуемую мощность, связанные с совокупностью физических эффектов, приборные проявления которых известны как „терагерцевая яма“", позволяют при реализации мощных THz-устройств отдать предпочтение приборам вакуумной эмиссионной электроники. Актуальной становится реализация миниатюрных аналогов ЛБВ (лампы бегущей волны) и ЛОВ (лампы обратной волны).

Как показывает практика, надежность и долговечность, а также стабильность характеристик электровакуумных приборов (ЭВП) в значительной степени определяются эмиссионной надежностью и долговечностью катодов. В настоящее время в большинстве производимых в мире ЭВП, в том числе СВЧ-диапазона длин волн, нашли применение термоэмиссионные металлопористые катоды (МПК) с различными добавками, предназначенными для уменьшения температурного коэффициента работы выхода электронов. Одним из основных требований, предъявляемых к МПК, особенно со стороны миниатюрных ламп бегущей волны миллиметрового и терагерцевого диапазонов, является повышение плотно- сти отбираемого тока, которое достигается увеличением рабочей температуры. Однако это приводит к росту скорости испарения активного вещества, входящего в состав МПК, и с учетом его ограниченного количества при малых габаритах ЭВП к уменьшению срока службы.

В настоящее время в производстве ЭВП СВЧ- и субтерагерцевого диапазонов рассматривается возможность использования кроме МПК источников электронов, функционирование которых основано на явлении полевой эмиссии электронов, которые обладают в отличие от термокатодов сверхвысоким быстродействием [2]. Одним из наиболее перспективных материалов для создания подобного типа устройств являются наноуглеродные пленочные структуры [3-5]. Показано, что при выборе режимов синтеза алмазографитовых нанокомпозитов в неравновесной микроволновой плазме паров этанола низкого давления может быть получено снижение порога полевой эмиссии электронов с 15-17 до 4-6 V/ $\mu \mathrm{m}$ и увеличение плотности автоэмиссионного тока в импульсах микросекундной длительности свыше $100 \mathrm{~A} / \mathrm{cm}^{2}$ [6].

Целью настоящей работы является исследование долговременной стабильности эмиссионных характеристик полевых источников электронов на основе композитных наноуглеродных пленочных покрытий с уровнем плотности автоэмиссионного тока не менее $100 \mathrm{~A} / \mathrm{cm}^{2}$ в нестационарных температурно-вакуумных условиях эксплуатации.

В качестве автоэмиссионных катодов использовались алмазографитовые пленочные структуры толщиной около $0.1 \mu \mathrm{m}$, осажденные на поликоровые пластины в 
микроволновой плазме паров этанола по методике, изложенной в [6]. Эмитирующей частью катодов были торцы алмазографитовой пленки, на расстоянии $7 \cdot 10^{-3} \mathrm{~m}$ от которых напылялся металлический контакт с прикладываемым катодным потенциалом. Измерительное устройство обеспечивало равную удаленность точек торца катода относительно анода из молибдена диаметром $5.5 \cdot 10^{-3} \mathrm{~m}$. Межэлектродный зазор составлял $4 \cdot 10^{-5} \mathrm{~m}$. Измерения проводились в вакуумной камере при давлении $P=(3-4) \cdot 10^{-5}$ Ра с использованием источника питания постоянного напряжения. Измерительная часть установки кроме источника питания включала записывающий многоканальный осциллограф, высоковольтный делитель напряжения, а также измерительное сопротивление ПЭВ-100 с номиналом $5.017 \cdot 10^{3} \Omega$ для наблюдения за изменениями напряжения и полевого тока.

Определение элементного состава поверхностей планарно-торцевых автоэмиссионных структур после электрических испытаний проведено с использованием автоэмиссионного сканирующего микроскопа MIRA 2 LMU производства фирмы Tescan, оснащенного системой Oxford INCA Energy 350. Система рентгеновского энергодисперсионного микроанализа Oxford INCA Energy 350 с детектором PentaFET-х3 обладает разрешением по $K_{\alpha} \mathrm{Mn}$ не хуже $133 \mathrm{eV}$ и площадью кристалла детектора $30 \mathrm{~mm}^{2}$, что позволяло проводить количественный анализ химических элементов от бора до урана.

После общего обезгаживания измерительного устройства, которое проводилось при прогреве встроенными нагревателями и давлении в вакуумной камере $1.6 \cdot 10^{-5} \mathrm{~Pa}$, обезгаживание анода осуществлялось автоэмиссионным током катода около $8 \cdot 10^{-3}$ А. Процесс сопровождался свечением, интенсивность которого увеличивалась с увеличением напряженности электрического поля и величины автоэмиссионного тока (рис. 1). Испытания на долговременную воспроизводимость характеристик катода проводились при циклических изменениях вакуума в диапазоне от $9 \cdot 10^{-6} \mathrm{~Pa}$ при работающем высоковакуумном насосе до $0.1 \mathrm{~Pa}$ к концу периода испытаний. Имитировались условия с аварийным отключением питающего напряжения и средств откачки, которые состояли в следующем. После испытаний автокатода при заданном напряжении в течение определенного промежутка времени (от 0.5 до $3 \mathrm{~h}$ в разных циклах) проводился замер вольт-амперных характеристик (BAX) и отключение источника питания. После остывания измерительного устройства отключались средства откачки, в результате чего давление в камере повышалось до $0.1 \mathrm{~Pa}$. Далее цикл испытаний с откачкой, подъемом напряжения, выдержкой при поданном напряжении и измерениями ВАХ повторялся.

На рис. 2 приведены изменения тока эмиссии (кривая I) и напряжения (кривая II) источника питания с нестабилизированным выходным напряжением в течение восьми циклов испытаний с суммарной длительностью свыше 13.5 h. В эту длительность время отключе-

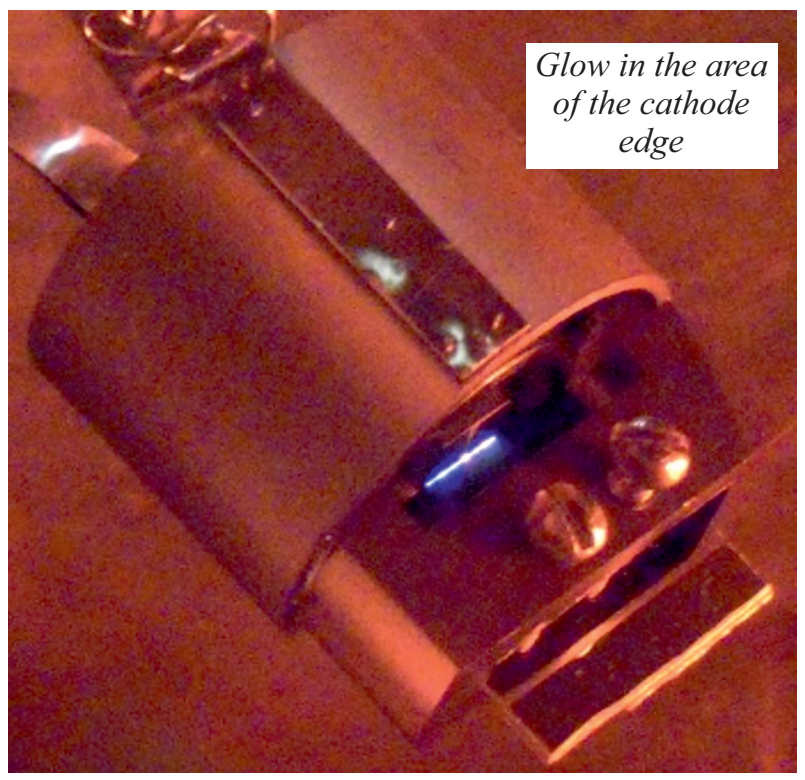

Рис. 1. Свечение торца катода при плотности полевого тока $1450 \mathrm{~A} / \mathrm{cm}^{2}$.

ния источника питания и средств откачки не включалось. Можно видеть, что полевой ток, как и следовало ожидать согласно Фаулеру и Нордгейму [7], очень чувствителен к нестабильности напряжения источника питания. При фиксированной напряженности поля около $50 \mathrm{~V} / \mu \mathrm{m}$ и циклическом изменении вакуумных условий эксплуатации автокатода полевой ток изменялся в пределах от $6 \cdot 10^{-3}$ до $8 \cdot 10^{-3} \mathrm{~A}$, что составляет около $25 \%$ при средней плотности токоотбора $1.3 \cdot 10^{3} \mathrm{~A} / \mathrm{cm}^{2}$.

На рис. 3 приведены ВАХ автокатода, полученные в начале испытаний и после завершения восьми циклов. Можно видеть, что, несмотря на неблагоприятные факторы, связанные с периодическими отключением питающего напряжения и ухудшением вакуума, полевая эмиссионная способность катода за время испытаний имела хорошую воспроизводимость. Об этом свидетельствуют, в частности, линейные зависимости токов от напряженности электрического поля, построенные в координатах Фаулера-Нордгейма для режимов, обеспечивающих сверхвысокую плотность тока полевой эмиссии.

С целью выяснения природы свечения после демонтажа вакуумного измерительного устройства проведены исследования поверхности анода. Изучение элементного состава его поверхности показало наличие углеродной фазы.

В работе [6] показано, что алмазографитовые пленочные композиты, использованные при испытаниях в качестве полевых источников электронов, представляют собой графитовые матрицы с погруженными в них алмазными нанокристаллитами. Поэтому, вероятнее всего, распылению подвергается графитовая компонента матрицы. Об этом может свидетельствовать высокая воспроизводимость ВАХ после различных циклов испы- 


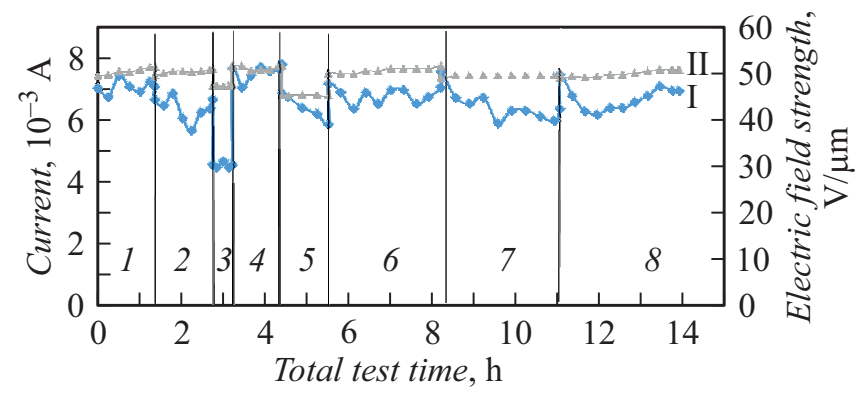

Рис. 2. Изменения полевого тока (I) и напряженности поля (II) в межэлектродном зазоре в течение восьми циклов долговременных испытаний (1-8- циклы испытаний).
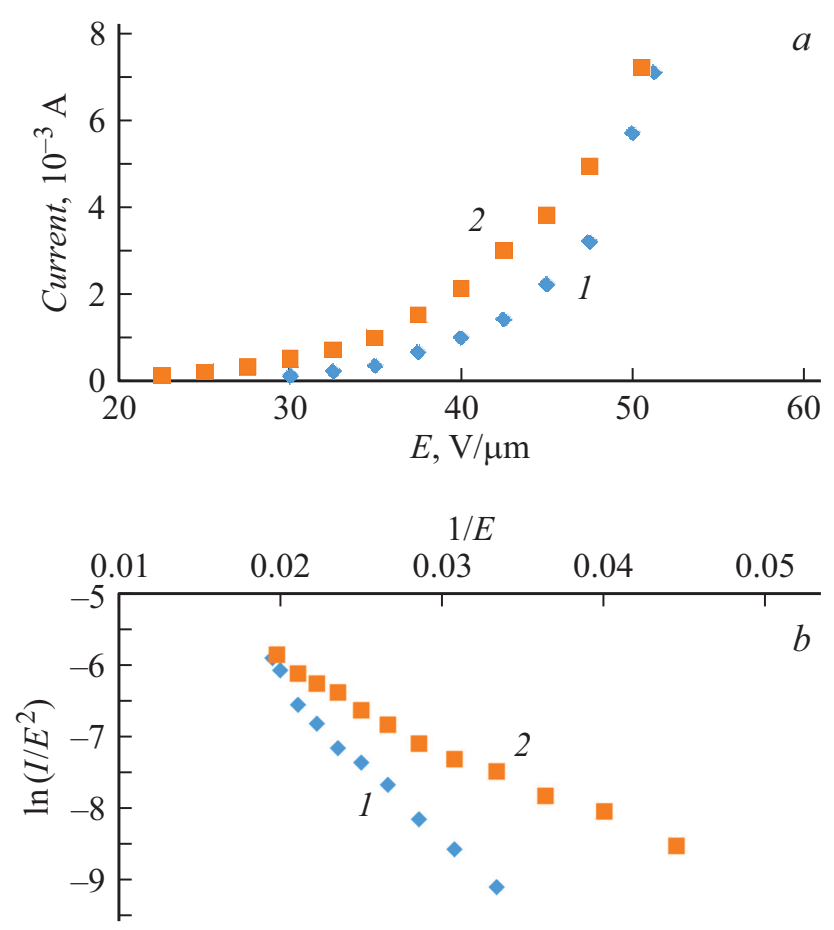

Рис. 3. ВАХ катода, полученные до (1) и после восьми циклов испытаний (2). $a-$ в линейных координатах; $b-$ в координатах Фаулера-Нордгейма.

таний, которая в предположении автоэмиссии не только с алмазных нанокристаллитов, но и с графитовых микровыступов могла бы претерпевать существенные трансформации. Преимущественное распыление графитовой фазы, находящейся в окружении алмазных нанокристаллитов, обусловлено более низкой теплопроводностью графита и, как следствие, более высокими температурой нагрева и коэффициентом распыления ионами остаточной атмосферы прибора. Распыленные атомы углерода ионизируются в сильном электрическом поле, образуя при рекомбинации в потоке электронов, эмитированных автокатодом, светящиеся вакуумно-плазменные катодные факелы [8].

Полученные результаты свидетельствуют о достаточно высокой долговременной воспроизводимости эмис- сионных характеристик полевых источников электронов на основе алмазографитовых пленочных структур. Они могут быть использованы для прогнозирования сроков службы автокатодов при эксплуатации в заданных силовых токовых режимах с возможным возникновением нестационарных температурно-вакуумных условий.

\section{Финансирование работы}

Работа выполнена при финансовой поддержке Российского научного фонда (проект № 16-19-10033) и Российского фонда фундаментальных исследований (проект № 19-38-90216).

\section{Конфликт интересов}

Авторы заявляют, что у них нет конфликта интересов.

\section{Список литературы}

[1] J.H. Booske, D.R. Whaley, W.L. Menninger, R.S. Hollister, C.M. Armstrong, in Modern microwave and millimeterwave power electronics, ed by R.J. Barker, N.C. Luhmann, J.H. Booske (Wiley-Interscience, N.Y., 2005), p. 171-245.

[2] G. Mittal, I. Lahiri, J. Phys. D: Appl. Phys, 47, 323001 (2014). DOI: $10.1088 / 0022-3727 / 47 / 32 / 323001$

[3] Г.Н. Фурсей, М.А. Поляков, А.А. Кантонистов, А.М. Яфясов, Б.С. Павлов, В.Б. Божевольнов, ЖТФ, 83 (6), 71 (2013). [G.N. Fursei, M.A. Polyakov, A.A. Kantonistov, A.M. Yafyasov, B.S. Pavlov, V.B. Bozhevol'nov, Tech. Phys., 58 (6), 845 (2013). DOI: 0.1134/S1063784213060121].

[4] K. Panda, J.J. Hyeok, J.Y. Park, K.J. Sankaran, S. Balakrishnan, I.N. Lin, Sci. Rep., 7, 16325 (2017).

[5] M. Sobaszek, K. Siuzdak, J. Ryl, M. Sawczak, S. Gupta, S.B. Carrizosa, M. Ficek, B. Dec, K. Darowicki, R. Bogdanowicz, J. Phys. Chem. C, 121, 20821 (2017).

[6] R.K. Yafarov, J. Commun. Technol. Electron., 64, 1431 (2019). DOI: $10.1134 / \mathrm{S} 1064226919120180$

[7] R.H. Fowler, LW. Nordheim, Proc. Roy. Soc. Lond. A., 119, 173 (1928).

[8] Г.А. Месяц, Взрывная электронная эмиссия (Физматлит, M., 2011). 